\title{
Professoras de Educação Infantil em época de Covid-19: relato de experiência sobre as atividades
}

\section{Early education teachers in the time of Covid-19: experience report on remote activities}

\author{
Andreia Mayumi Oshiro ${ }^{1}$ \\ Alessandra Cristina dos Santos ${ }^{2}$ \\ Ana Lúcia Soares 3 \\ Andrea Maria Alves Pinto Gomes 4 \\ Maria Augusta Fhal 5 \\ Rita de Cássia dos Santos Gomes ${ }^{6}$ \\ Andreia Cristina Metzner ${ }^{7}$
}

\begin{abstract}
Resumo
A pandemia de Covid-19 impactou diversos setores, dentre eles, o educacional. Nesse contexto, as Secretarias de Educação tiveram que reestruturar as suas redes de ensino e adotar medidas para evitar a disseminação da doença. Uma dessas medidas foi a substituição das aulas presenciais por remotas. O presente artigo tem como objetivo compartilhar as experiências de seis professoras sobre as atividades que estão sendo desenvolvidas na primeira etapa da Educação Básica. Essas docentes atuam em um Centro Municipal de Educação Infantil localizado em uma cidade do interior do estado de São Paulo e lecionam em turmas pré-escolares. Para tanto, o método utilizado foi o relato de experiência.
\end{abstract}

Palavras-chave: Educação Infantil. Aulas remotas. Pandemia. Covid-19.

\begin{abstract}
The Covid-19 pandemic caused by coronavirus has affected several sectors, including the educational one. In this context, Education Departments have restructured their schools and implemented actions aiming at preventing the spread of contagious. One of these actions was the replacement of face-to-face teaching by remote teaching. Accordingly, this article aims to share experiences of six early education teachers on activities that have been developed in this phase of the Basic Education. The teachers involved in the present study work at a Public Center for Early Childhood Education located in a city of São Paulo State. The experience report method was used.

\footnotetext{
${ }_{1}^{1}$ Prefeitura Municipal de São Carlos/SP. E-mail: andreia.oshiro@professor.saocarlos.sp.gov.br

${ }^{2}$ Prefeitura Municipal de São Carlos/SP. E-mail: alessandra.santos@professor.saocarlos.sp.gov.br

3 Prefeitura Municipal de São Carlos/SP. E-mail: ana.soares@professor.saocarlos.sp.gov.br

${ }^{4}$ Prefeitura Municipal de São Carlos/SP. E-mail: andrea.gomes@professor.saocarlos.sp.gov.br

${ }^{5}$ Prefeitura Municipal de São Carlos/SP. E-mail: maria.fahl@professor.saocarlos.sp.gov.br

${ }^{6}$ Prefeitura Municipal de São Carlos/SP. E-mail: rita.gomes@professor.saocarlos.sp.gov.br

7 Prefeitura Municipal de São Carlos/SP. E-mail: andreia.metzner@ educacao.saocarlos.sp.gov.br .
} 
Key words: Early education. Remote teaching. Pandemic. Covid-19.

\section{Introdução}

A Covid-19, doença causada por um tipo de coronavírus, foi identificada pela primeira vez final do ano de 2019, na cidade de Wuhan, na China. Devido à sua rápida transmissão, essa doença viral se espalhou pelo mundo e, em 11 de março de 2020, foi caracterizada como uma pandemia, registrando casos de infecção e mortes "em mais de 185 países, tornando assim, uma ameaça à saúde humana e afetando a dinâmica socioeconômica do planeta" (SANTOS; TRAJANO JÚNIOR, 2020, p. 01).

Diante desse cenário, a maioria das Secretarias Estaduais e Municipais de Educação brasileiras resolveu decretar a suspensão das aulas presenciais na segunda quinzena de março. Essa medida foi tomada com o intuito de evitar a transmissão da doença, proteger a saúde e preservar a vida de toda a comunidade escolar.

A escola é considerada, de acordo com Arruda (2020), um dos espaços mais temidos pelo risco da transmissão da Covid-19, "pois a sua multiplicidade e heterogeneidade cria vínculos entre aqueles que são menos propensos aos sintomas graves da doença (jovens) a todos os demais que podem ser até mortalmente propensos" (p. 259).

Destarte, em 19 de março de 2020, o Ministério da Educação autorizou por meio da Portaria n. ${ }^{\circ} 343$, em caráter excepcional, a substituição das aulas presenciais por aulas em meios digitais enquanto durar a situação de pandemia (BRASIL, 2020a). Esta Portaria, a princípio, havia determinado a substituição das aulas presenciais por um período de 30 dias, porém, esse ato administrativo normativo foi revogado e a Portaria n. ${ }^{\circ} 544$ de 16 de junho de 2020 estendeu o prazo até 31 de dezembro de 2020 (BRASIL, 2020b).

Para atender as normativas do Ministério da Educação e tentar amenizar as perdas no setor educacional, os estados e os municípios reestruturaram as suas redes de ensino e aderiram às aulas não presenciais. No caso da nossa cidade, as aulas remotas foram iniciadas no dia 01 de junho de 2020.

Isto posto, o objetivo desse estudo é compartilhar as experiências de um grupo de professoras de Educação Infantil em relação às adaptações ao ensino remoto em tempo de Covid-19. Essas docentes atuam em um Centro Municipal de Educação Infantil (CEMEI) localizado em uma cidade do interior do estado de São Paulo e lecionam em turmas da Fase 6 , referente às crianças que cursam o último ano da pré-escola.

Para tanto, o método utilizado foi o relato de experiência. Nesse método, o pesquisador discrimina todo o contexto e qualifica as suas ações, de forma sequencial, até chegar à conclusão da experiência (FORTUNATO, 2018). Dessa forma, as autoras procuraram descrever a transição inicial do ensino presencial para o remoto, partindo das estratégias adotadas pela unidade escolar até a elaboração das vivências encaminhadas 
às famílias.

O relato descrito neste estudo abrangeu o período de junho a agosto de 2020 e teve como foco as percepções e vivências pessoais de seis professoras de Educação Infantil sobre o ensino remoto no contexto inicial da pandemia de Covid-19.

As professoras reuniam-se semanalmente, junto com a direção da escola, para discutirem sobre o andamento das atividades pedagógicas não presenciais. E, durante esses encontros, cada docente explanava o que estava ocorrendo em sua turma, e a diretora fazia o acompanhamento e o registro dos relatos. É importante ressaltar que todas atuavam com a mesma faixa etária e, portanto, o planejamento das vivências era feito em conjunto.

Os dados foram coletados a partir das interações estabelecidas entre professoras e famílias por meio do WhatsApp. Os contatos feitos nesse aplicativo permitiram tanto a verificação das atividades realizadas pelas crianças por meio das imagens e vídeos postados no grupo da turma quanto a reunião de informações sobre as dificuldades das famílias em acompanhar o ensino remoto.

A unidade escolar pesquisada localiza-se em um bairro próximo ao centro da cidade, porém, a clientela é diversificada atendendo também alunos de bairros mais distantes, abrangendo famílias com contextos socioeconômicos diferentes.

No que concerne aos sujeitos envolvidos na pesquisa, todos concordaram expressamente em participar do estudo.

Para a discussão dos dados elencamos três categorias: 1-) Retomada das atividades pedagógicas não presenciais; 2-) Interação com as famílias; 3-) Roteiro de atividades.

\section{Retomada das atividades pedagógicas não presenciais}

Em nosso município, as aulas foram suspensas a partir do dia 20 de março de 2020. Essa repentina interrupção fez com que todo o professorado interrompesse o trabalho pedagógico iniciado em fevereiro. O fechamento total das escolas também afetou as famílias das crianças que tiveram que reorganizar suas rotinas e de seus filhos visando atender as medidas de proteção para evitar a contaminação e disseminação da doença.

Durante o período de suspensão das aulas, a Secretaria Municipal de Educação (SME) antecipou o recesso escolar para o período de 23 de março de 2020 a 06 de abril de 2020. Posteriormente, elaborou estratégias com o intuito de retomar as atividades pedagógicas o mais breve possível.

Então, na última semana do mês de maio, a direção da escola entrou em contato com o corpo docente por meio de WhatsApp, informando que a SME adotou a proposta de ensino remoto e que nos dias 28 e 29 de maio haveria uma reunião virtual com a 
equipe docente para o planejamento das atividades pedagógicas não presenciais.

Nesse momento, muitas questões surgiram: ensino remoto é o mesmo que ensino a distância? Como vamos ensinar remotamente as crianças pequenas? É possível ensinálas de forma não presencial? Quais recursos seriam utilizados?

Diante disso, o corpo docente reuniu-se virtualmente com a direção da escola para receber algumas orientações e esclarecimentos sobre o ensino remoto. Após a reunião, as autoras perceberam que esse tipo de ensino difere da Educação a Distância (EaD). De acordo com Joye, Moreira e Rocha (2020) "a EaD é uma modalidade de ensino complexa e que tem uma legislação própria” (p. 23), além disso, está ligada intensamente ao uso de tecnologias digitais de informação e comunicação. Já o ensino remoto "não tem legislação própria, assim como não é uma modalidade de ensino" (p. 23), são atividades pedagógicas que ocorrem fora da sala de aula e podem ser mediadas por tecnologias ou por materiais impressos.

Sentimos certo alívio ao saber que a Educação Infantil não seria oferecida por EaD, pois compreendemos que o ensino de crianças pequenas deve ser baseado em vivências que permitam interações com o outro e com o meio.

Em um curto período, pois no dia 01 de junho de 2020 seriam retomadas as atividades pedagógicas não presenciais, tivemos que aprender a operar as mídias digitais e replanejar a prática docente a partir do novo contexto.

As estratégias para realização das atividades escolares não presenciais foram elaboradas em conjunto com a equipe escolar. Dessa forma, o apoio e a troca de experiências/conhecimentos entre os pares foram fundamentais para o bom andamento do trabalho.

\section{Interação com as famílias}

O primeiro passo para a retomada das atividades escolares foi estabelecer o contato com os pais ou responsáveis das crianças, por meio do recurso escolhido por cada professor.

Decidimos usar o WhatsApp, pois este é um aplicativo multiplataforma de mensagens instantâneas e chamadas de voz, além de ser bastante popular e usado por muitas pessoas. Em seguida, solicitamos à direção da escola a lista de pais com seus respectivos contatos de celulares. Ao fazer isso, nos deparamos com a dificuldade de contatar alguns familiares que não atualizaram os números de telefone na secretaria da escola. Dessa forma, foi preciso entrar em contato com outras pessoas até conseguirmos o número correto. Para isso, recorremos aos aparelhos particulares (celulares, computadores, tablet) e custeamos o seu uso com recurso próprio (internet e manutenção dos aparelhos).

Esse contato direto com as famílias foi imprescindível para o início das atividades, 
pois a nossa escola atende crianças na faixa etária entre 4 anos e 5 anos e 11 meses, ou seja, Educação Infantil (crianças pequenas), portanto, os pais/responsáveis seriam os mediadores entre a escola e a criança.

Nesse processo de ensino e aprendizagem, no qual houve uma mudança brusca na rotina escolar, os pais/responsáveis são peças fundamentais na educação das crianças, tanto no incentivo ao desenvolvimento das atividades sugeridas na organização da rotina de estudos e na conservação do vínculo entre a escola e a família/criança.

Porém, a maioria deles afirmou não ter disponibilidade de tempo e formação profissional para ensinar os seus filhos. Isso mostra que a interpretação das famílias está equivocada em relação às vivências lúdicas propostas pelas professoras, pois não é exigido conhecimento técnico para desenvolvê-las, mas sim, é preciso disponibilizar um pouco de tempo e paciência para participar das atividades sugeridas junto com as crianças.

É importante ressaltar que a interação com as famílias não aconteceu somente para o envio das sugestões de vivências lúdicas, mas estivemos à disposição para orientar e esclarecer dúvidas durante todo o horário de trabalho.

Outro problema encontrado nessa interação família e escola foi que, em alguns momentos, nos deparamos com pais buscando atividades de cobrir linhas pontilhadas na internet e imprimindo-as para que as crianças pudessem fazê-las em casa, indo na contramão da nossa proposta pedagógica que está alinhada a Base Nacional Comum Curricular (BNCC). Ainda há familiares que não dão retorno sobre as sugestões, às vezes por falta de acesso à internet, outras por falta de interesse e/ou de tempo.

Por meio desse contato, notamos que os pais/responsáveis apresentam duas visões distintas em relação à Educação Infantil. Algumas famílias ainda possuem a visão assistencialista, em que acreditam que criança recebe somente os cuidados e brinca a maior parte do tempo na escola, dessa forma, estas não veem importância nas atividades sugeridas, pois acreditam que as brincadeiras não são conteúdos de ensino. Por outro lado, há familiares com uma visão escolarizada e tradicional da Educação Infantil, em que a criança deve aprender letras, números e até ser alfabetizada. Em razão disso, esses pais imprimem atividades ou compram cartilhas para que as crianças copiem ou treinem o traçado das palavras.

Nas duas visões citadas, podemos notar que as brincadeiras não são vistas pelos familiares como atividades fundamentais para a aprendizagem e o desenvolvimento infantil, por não terem o conhecimento das orientações trazidas pela BNCC. De acordo com esse documento, os eixos estruturantes das práticas pedagógicas da Educação Infantil são as interações e a brincadeira (BRASIL, 2018). E, especificamente sobre as brincadeiras, aponta que "a interação durante o brincar caracteriza o cotidiano da infância, trazendo consigo muitas aprendizagens e potenciais para o desenvolvimento integral das crianças" (BRASIL, 2018, p. 37). 
Dessa forma, será primordial realizar um trabalho contínuo de formação e conscientização das famílias sobre a importância das brincadeiras e das vivências lúdicas nessa etapa da Educação Básica para que a intencionalidade educativa não se perca durante esse período de atividades remotas.

\section{Roteiro de atividades}

Com a pandemia as reuniões pedagógicas tiveram que ser adaptadas às novas condições de trabalho e passaram a ser realizadas de forma online, por meio da plataforma Google Meet. Tivemos que aprender a lidar com esta ferramenta e incluí-la no nosso cotidiano, pois todas as reuniões (com professores, diretores e coordenadores) estavam acontecendo por meio dela.

As professoras que lecionavam para a mesma faixa etária se agruparam e, semanalmente, reuniam-se virtualmente para o planejamento das atividades que iriam compor o roteiro.

Dessa forma, ao longo da semana, nós trocávamos algumas ideias pelo WhatsApp para a escolha do tema, vídeos, histórias, jogos, brincadeiras etc. E na reunião virtual era feita a discussão sobre todo o material coletado, bem como, os aspectos positivos e negativos de cada item. Por fim, o Roteiro de Atividades Semanal era elaborado e disponibilizado aos familiares.

Na primeira reunião, conversamos a respeito do tipo de atividade que deveríamos sugerir às famílias. Compreendemos que os pais/responsáveis não possuem a formação profissional pedagógica e nem os conhecimentos específicos para que possam intervir adequadamente, e em razão disso priorizamos as atividades lúdicas que enfatizam a interação da criança com seus familiares, como brincadeiras e jogos que promovem a diversão, fortalecem os vínculos entre os participantes, e também contribuem para o aprendizado de diversas habilidades que constam na BNCC (BRASIL, 2018), garantindo os direitos das crianças: conviver, brincar, expressar, explorar, conhecer-se e participar.

Antes de iniciar o primeiro encaminhamento da Rotina Semanal, orientamos os pais sobre as atividades no sentido em que eles poderiam realizar as adaptações que acharem primordiais em relação ao material e executá-las conforme a rotina de cada família e o tempo disponível. Ademais, foram propostas atividades que as famílias pudessem realizar com materiais simples.

Para a formatação da Rotina Semanal recorremos a ferramenta Canva que está disponível na internet, como o modelo abaixo: 


\title{
ROTINA SEMANAL
}

\author{
FASE 6 - SEMANA 15/06 - 19/06
}

NESTE MOMENTO DE ISOLAMENTO SOCIAL QUE ESTAMOS VIVENDO, A PARTICIPAÇÃO DOS PAIS NA VIDA ESCOLAR DA CRIANÇA É FUNDAMENTAL E DE GRANDE IMPORTÂNCIA PARA O SEU DESENVOLVIMENTO.

SEGUE AS "VIVÊNCIAS LÚDICAS" A SEREM REALIZADAS AO LONGO DESSA SEMANA COM O TEMA "FAMÍLIA".

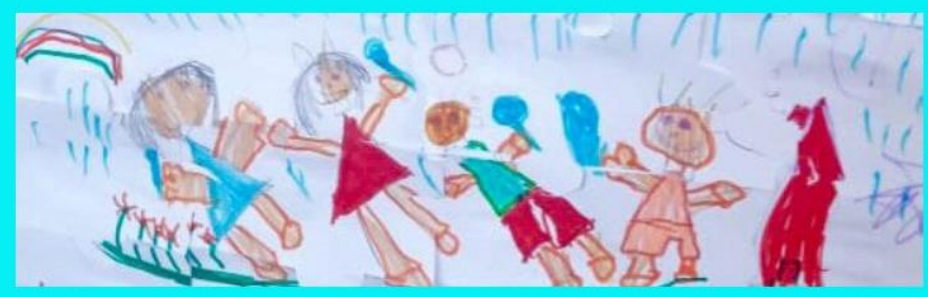

Atividade - Vídeo "As Famílias do Mundinho - Varal de Histórias"

CANAL VARAL DE HISTÓRIAS (As Famllias do Mundinho).

Disponível em: https://youtu.be/PAg80TpIqX8. Acesso em: 10 jun. 2020.

Atividade Complementar referente ao conteúdo do Vídeo "As Famílias do Mundinho - Varal de Histórias"

A criança deverá desenhar a sua família.

2

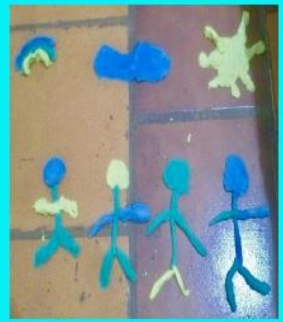

\section{Atividade - Vídeo "Quintal da}

Cultura - Minha Família"

$$
\begin{aligned}
& \text { CANAL QUINTAL DA CULTURA (Minha } \\
& \text { Família). }
\end{aligned}
$$

Disponivel em: https://youtu.be/1ZM5EUcv2js. Acesso em: 10 jun. 2020.
Procedimento - Vídeo "As Famílias do Mundinho - Varal de Histórias"

- Assistir o vídeo;

- Conversar com os membros da família sobre a sua família.

Procedimento - Atividade Complementar referente ao conteúdo do Vídeo "As Famílias do Mundinho - Varal de Histórias"

Vamos montar um quebra-cabeça?

- Com o auxílio de um membro da família a criança deve recortar o desenho da família em 6 partes, transformando-o em um quebra-cabeça;

- Em seguida a criança deve montar e brincar pra valer com o seu quebracabeça da família.

Fonte: Elaboração dos Autores 
- Revista de Iniciação à Docência, v. 6 , n. 1 , 2021 -

Publicação: julho, 2021 - ISSN 2525-4332

Figura 2: Rotina Semanal - Parte2

\section{Atividade Complementar referente ao conteúdo do Vídeo "Quintal da \\ Cultura - Minha Família" \\ Atividade "CAIXA SURPRESA DA FAMÍLIA"}

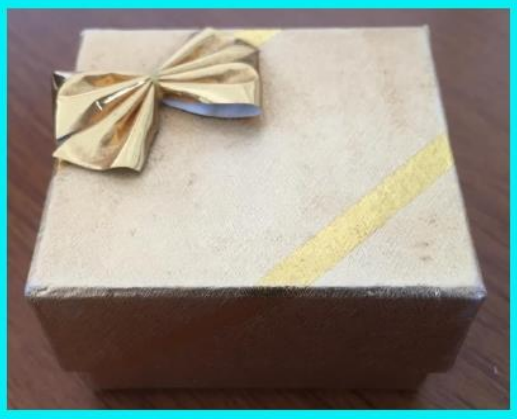

Procedimento - Atividade Complementar referente ao conteúdo do Vídeo "Quintal da Cultura - Minha Família"

\section{Atividade "CAIXA SURPRESA DA FAMÍLIA"}

- Separar uma caixa de sua preferência (ex: sapato, presente etc) e também fotos de parentes próximos da sua família (ex: avós, primos, tios etc);

- Em um ambiente agradável a família senta em roda;

- Colocar as fotos dentro da caixa;

- Em seguida a criança retira uma foto da caixa e os demais membros da família (de forma organizada) fala sobre a pessoa da foto (ex: nome, grau de parentesco, quem é?, do que ela gosta?, como ela é? etc);

- E assim sucessivamente até finalizar as fotos da caixa.

\section{3}

Atividade - Clipe "Mundo Bita -

Nossa Família"

CANAL MUNDO BITA (Nossa familia - clipe infantil).

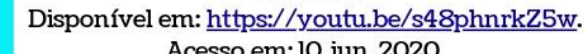

Disponível em: $\underline{\text { https://youtu.be/s48phnrkZ5w. }}$.
Acesso em: 10 jun. 2020.

\section{Procedimento - Clipe "Mundo Bita - Nossa Família"}

- Assistir o clipe, cantar e dançar quantas vezes quiser;

- Conversar sobre a sua família (quem faz parte da sua família, lembrar de fatos, passeios, histórias da sua família etc);

- Organizar um piquenique em família (permitir que a criança escolha o lugar da casa que farão o piquenique, a comida, a bebida etc);

- Realizar o piquenique de maneira divertida, aproveitando o momento em família.

\section{SUGESTÕES PARA FAZER EM FAMÍLIA COM A CRIANÇA}

Estamos encaminhando aqui sugestões de brincadeiras para realizarem em família com a criança.

Pode ser num dia qualquer ou após o piquenique por exemplo.

O importante é se divertirem!!!

C Anos). Disponível em: https://youtu.be/iubvqTsxwGE. Acesso em: 10 jun. 2020.

CANAL TURMA DO CRISTÃOZINHO (Brincadeiras Antigas). Disponível em: https://youtu.be/_6dOZPWQ9Cs. Acesso em: 10 jun. 2020.

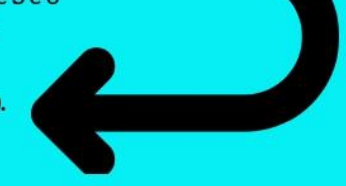

Fonte: Elaboração dos Autores 
Após o encaminhamento da Rotina Semanal por meio do grupo de WhatsApp observamos que muitos familiares visualizavam a rotina, porém, poucos nos enviavam fotos ou vídeos das crianças realizando as atividades. Acreditamos que algumas pessoas não querem expor a imagem de seus filhos, outros porque não lembram de tirar a foto no momento da atividade, e há aqueles que não conseguem realizar as vivências por diversos motivos como, por exemplo, a falta de tempo ou de interesse.

Em relação às devolutivas dos familiares, notamos que a maior parte realiza somente as atividades que envolvem o desenho e a escrita. Já as vivências lúdicas que envolvem brincadeiras, rodas de conversa, experiências, jogos e que demandam mais atenção e orientação de um adulto não tem a mesma adesão.

A princípio pensamos que os familiares poderiam estar com dificuldades em compreender a execução das atividades lúdicas, então, reforçamos com mensagens no grupo de WhatsApp a nossa disposição para qualquer dúvida. Porém, foram poucos os familiares que nos procuraram para esclarecimentos sobre as atividades propostas.

A seguir, apresentamos algumas fotos da Rotina Semanal exemplificado anteriormente, cujo tema foi a Família. As fotos estão relacionadas à Atividade 1, em que as crianças teriam que desenhar a sua família e montar um quebra-cabeça para brincar depois. Em relação às Atividades 2 e 3, que propõem rodas de conversa sobre o tema, não recebemos nenhuma imagem, áudio ou vídeo.

Figura 3: Criança desenhando a família

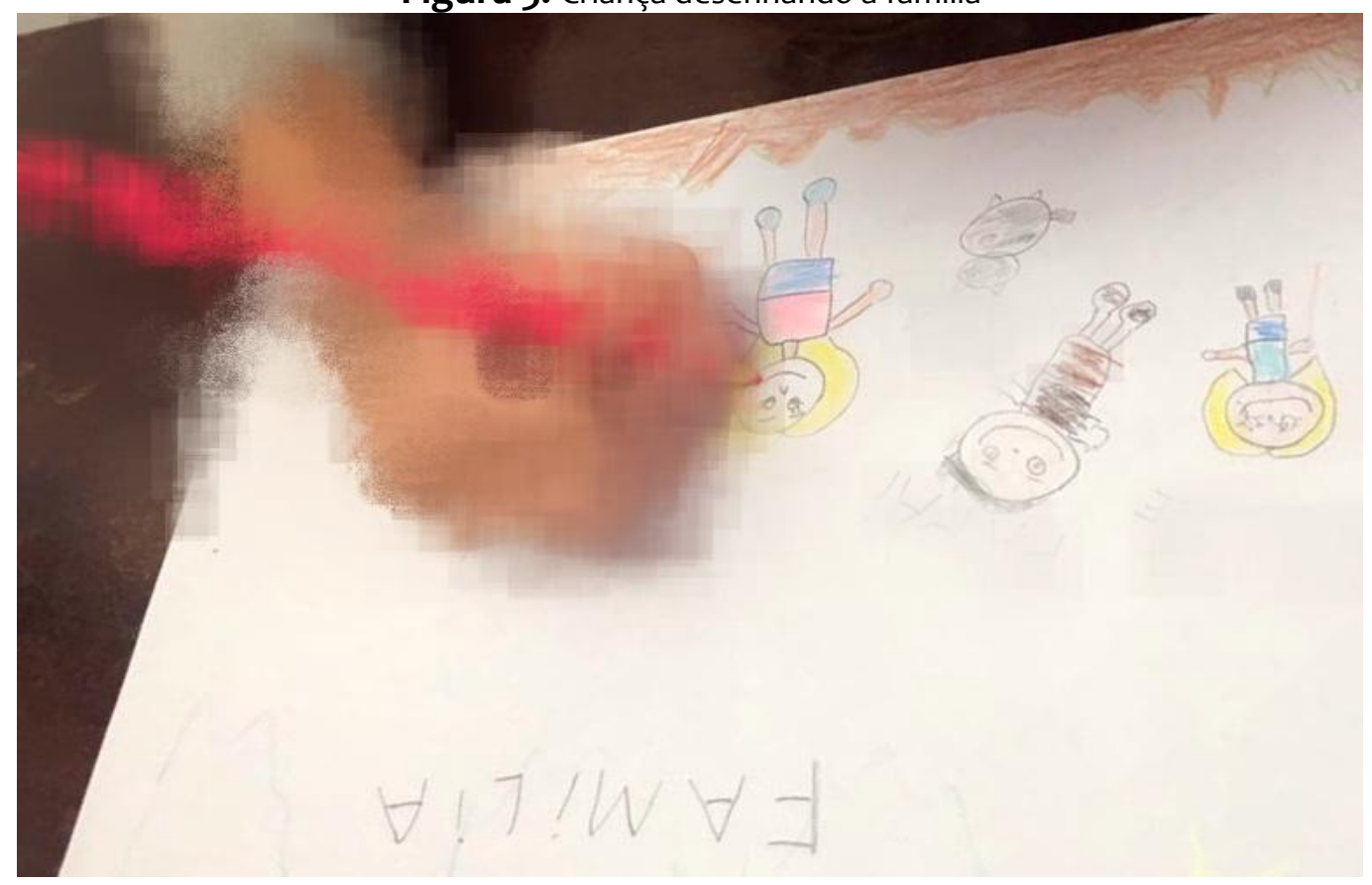

Fonte: Arquivo Pessoal da Família da Criança 
Figura 4: Quebra-cabeça

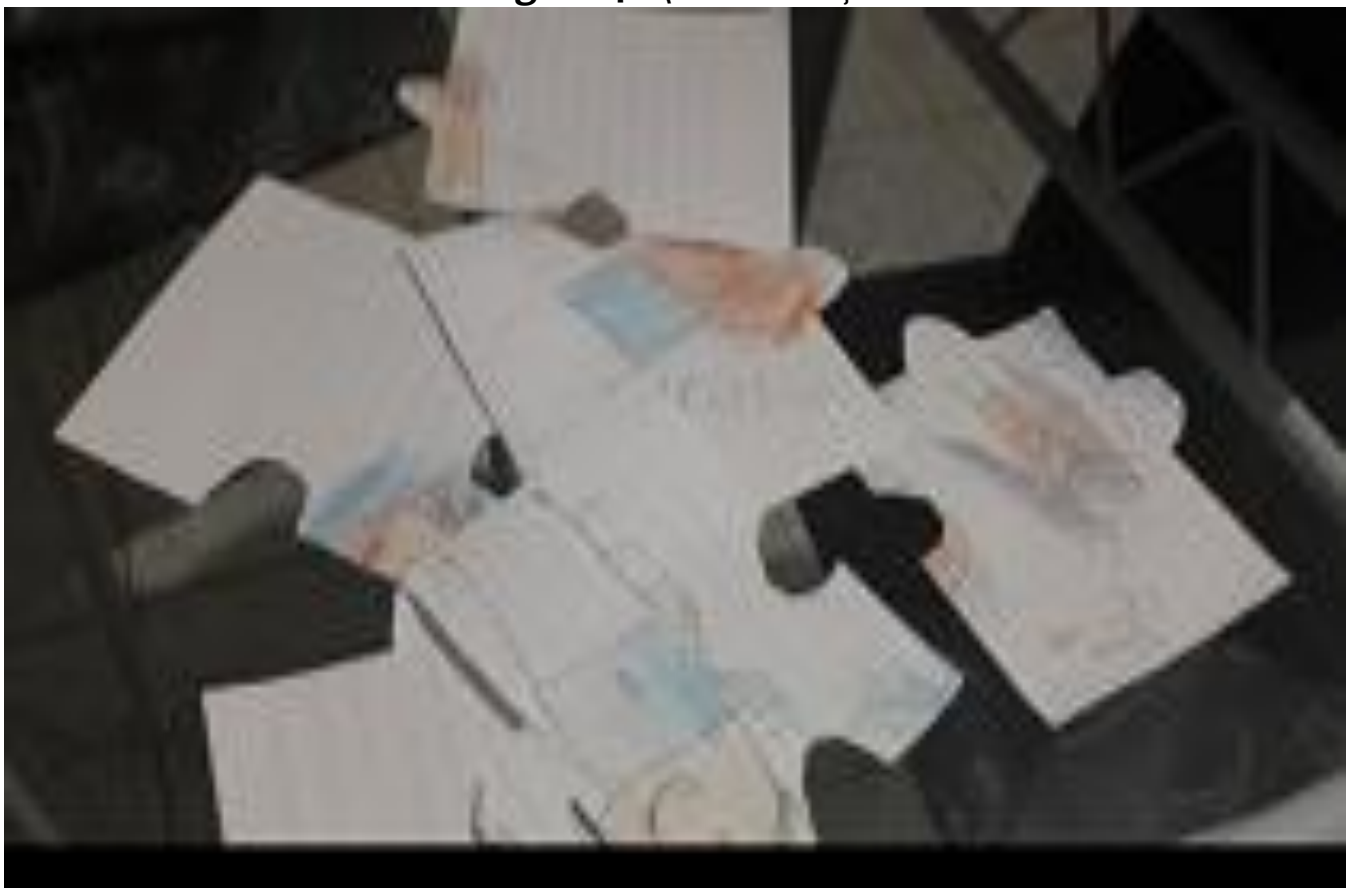

Fonte: Arquivo Pessoal da Família da Criança

A nossa expectativa é que, com o passar do tempo e com a prorrogação das aulas não presenciais, os familiares compreenderão a importância da realização das atividades propostas pelo professor e reservarão um período do dia ou da semana para sua execução. Enquanto isso, nós continuamos encaminhando nos grupos as Rotinas Semanais, bem como, mensagens, vídeos e textos informativos sobre a importância das vivências lúdicas para o desenvolvimento da criança visando sensibilizar e motivar as famílias.

\section{Considerações Finais}

Acreditamos que a relação entre a família e a criança se tornará diferente após a pandemia, pois neste período de isolamento social em que as crianças deixaram de ir à escola e permaneceram o tempo todo com os seus pais ou com pessoas muito próximas, fez com que esses vínculos se fortalecessem.

A nossa escola atende crianças de período integral, e elas passam 9 horas contínuas na escola (das $7 \mathrm{~h}$ às $17 \mathrm{~h}$ ), e muitas usam van escolar e chegam em casa somente no fim da tarde. Portanto, permaneciam a maior parte do tempo no ambiente escolar, interagindo e convivendo com os coleguinhas e professores. Agora, essa rotina foi invertida, ela está em contato direto com os seus familiares. Isso fez com que as famílias se aproximassem das crianças e, desse modo, puderam conhecer melhor os seus filhos. Nesse contexto, temos a expectativa que as relações familiares sejam valorizadas, que neste processo de convívio "forçado", os pais tenham compreendido a importância de seu papel na vida da criança e estejam mais presentes no futuro. 
Acreditamos também que as retomadas das aulas presenciais só devem ocorrer depois de uma vacina e/ou da descoberta de remédios cientificamente eficazes e capazes de garantir um retorno seguro, pois, em meio a uma pandemia é uma atitude inviável o retorno à escola, ainda mais na Educação Infantil que requer a socialização e a interação entre criança/criança e criança/professor.

Ao seguirmos os protocolos de segurança sugeridos pela Organização Mundial de Saúde (OMS), não será possível contemplar os seis direitos da aprendizagem disponibilizados na BNCC, pois a Educação Infantil está pautada no contato físico, na experimentação, no brincar, na interação, entre outros. $\mathrm{E}$ a imposição do distanciamento gerará sofrimento à criança, se pensarmos no educar sem explorar/tocar/socializar, na limitação de suas interações sociais e na falta de maturidade para seguir rigorosamente os protocolos.

Por fim, esperamos que a volta às aulas presenciais em nosso município ocorra com base no controle da doença, seja feita de forma gradual e cautelosa, bem como, siga os protocolos de saúde e de segurança, pois, durante a pandemia de Covid-19, a saúde e a preservação da vida devem ser colocadas antes da aprendizagem, priorizando a proteção dos profissionais da educação, crianças e familiares.

\section{Referências}

ARRUDA, Eucidio Pimenta. Educação Remota Emergencial: elementos para políticas públicas na educação brasileira em tempos de Covid-19. EmRede, v. 7, n. 1, p. 257-275, 2020.

BRASIL. Portaria n..$^{\circ}$ 343, de 17 de março de 2020. Dispõe sobre a substituição das aulas presenciais por aulas em meios digitais enquanto durar a situação de pandemia do Novo Coronavírus - COVID-19. Diário Oficial da União, 2020a. Seção 1, p. 39. Disponível em: http://www.in.gov.br/en/web/dou/-/portaria-n-343-de-17-de-marco-de-2020-248564376 Acesso em: 11 julho 2020.

BRASIL. Portaria n. ${ }^{\circ}$ 544, de 16 de junho de 2020. Dispõe sobre a substituição das aulas presenciais por aulas em meios digitais, enquanto durar a situação de pandemia do novo coronavírus - Covid-19, e revoga as Portarias MEC n 343, de 17 de março de 2020, $n^{\circ} 345$, de 19 de março de 2020, e n 473, de 12 de maio de 2020. Diário Oficial da União, 2020b. Seção 1, p. 62. Disponível em: https://abmes.org.br/arquivos/legislacoes/Portaria-mec-5442020-06-16.pdf. Acesso em: 11 julho 2020.

BRASIL. Ministério da Educação. Secretaria da Educação Básica. Base Nacional Comum Curricular. Brasília/DF, 2018.

FORTUNATO, Ivan. O relato de experiência como método de pesquisa educacional. In: Fortunato, Ivan; SHIGUNOV NETO, Alexandre (org). Método(s) de Pesquisa em Educação. São Paulo: Edições Hipótese, 2018. p.37-50. 
- Revista de Iniciação à Docência, v. 6 , n. 1, 2021 -

Publicação: julho, 2021 - ISSN 2525-4332

JOYE, Cassandra Ribeiro.; MOREIRA, Marília Maia; ROCHA, Sinara Socorro Duarte.

Educação a distância ou atividade educacional remota emergencial: em busca do elo perdido da educação escolar em tempos de COVID-19. Research, Society and

Development, v. 9, n. 7, p.1-29, 2020.

SANTOS, Javan Sami Araújo; TRAJANO JÚNIOR, Salatiel Braga. Propositivas de um plano de contigenciamento em tempos de COVID-19: da secretaria às escolas de Rio Largo - AL. Revista Educação Básica em Foco, v.1, n.1, p.1-5, 2020.

$* * *$

Recebido: 04.04.2021

Aprovado: 18.06.2021 